\title{
Perancangan Desain Mural Cerita Pewayangan Hanoman Obong untuk World Puppet Festival 2020
}

\author{
Julia Intan Pusphita Subagyo dan Senja Aprela Agustin \\ Departemen Desain ProdukInstitut Teknologi Sepuluh Nopember (ITS) \\ e-mail: senja@prodes.its.ac.id
}

\begin{abstract}
Abstrak-April 2019, Indonesia menjadi tuan rumah 23rd UNIMA Congress World Puppet Festival yang dilaksanakan di Gianyar, Bali. Pada festival tersebut Indonesia menampilkan keragaman pewayangan Indonesia, salah satunya Wayang Golek. Lakon Gugurnya Dasamuka dan Hanoman Obong merupakan lakon pewayangan dengan salah satu sudut pandang dari kisah Ramayana yang jarang diangkat. Tuan rumah membutuhkan media kontemporer dalam rangkaian acara untuk mengenalkan keragaman pewayangan Indonesia kepada pengunjung dengan interaktif. Perancang melihat potensi media untuk mengenalkan Hanoman Obong kepada pengujung festival. Dalam perancangan ini, informasi yang menjadi bahan pertimbangan dalam menentukan strategi perancangan digali melalui metode penelitian kualitatif. Metode kualitatif yang dilakukan diantaranya observasi replika relief Candi Prambanan ke museum wayang; depth interview hasil eksplorasi visual (desain karakter, desain instalasi dan desain mural) kepada ahli wayang dan ahli mural/graffiti artist; dan kepada UNIMA Indonesia selaku stakeholder perancangan. Sementara itu, pengumpulan data sekunder menggunakan data yang didapat dari studi literatur mengenai kisah pewayangan Hanoman Obong serta visualisasi lakon. Media luaran dari perancangan ini adalah desain lingkungan pop-up mural installation Hanoman Obong yang interaktif dengan ukuran 15 meter x 4,88 meter untuk World Puppet Festival 2020. Pada perancangan ini di dalamnya ada kegiatan dan cerita yang didesain dengan dua alur, yakni mulai dari percintaan Rama dan Shinta dan yang kedua Hanoman dari Kiskenda. Kedua alur ini akan bertemu di area Alengka sebagai puncak cerita. Empat tokoh utama dalam Hanoman Obong diantaranya Hanoman, Rama, Shinta, dan Rahwana (Dasamuka) serta beberapa tokoh figuran seperti Subali, Sugriwa dan Trijata. Guide booklet area Forest dan Kiskenda dirancang untuk memandu pengunjung melakukan interaksi agar memberikan experience dan diharapkan dapat mengenali sudut pandang lain lakon Hanoman Obong. Sebagai kebutuhan percancangan ini juga dirancang identitas visual beserta merchandise berupa patch dan juga sticker pack.
\end{abstract}

Kata Kunci-Pewayangan, Ramayana, Hanoman Obong, Mural, Interaktif.

\section{PENDAHULUAN}

$\mathrm{P}$ RESIDEN UNIMA Indonesia, TA Samodra Sriwidjaja menjelaskan bahwa Indonesia akan menjadi tuan rumah 23rd UNIMA Congress World Puppet Festival yang dilaksanakan di Gianyar, Bali, bulan April 2020. Berdasarkan wawancara yang dilakukan oleh perancang, beliau mengatakan bahwa penampilan Indonesia dalam festival kali ini mengusung keragaman dimulai oleh dalang muda dari Bali, Wayang Bali, Tari Barong, Tari Kecak, hingga pementasan Wayang Kulit dan Wayang Golek. Lakon Gugurnya Dasamuka dipentaskan dengan Wayang Golek sebagai wayang yang paling populer dari Jawa Barat.

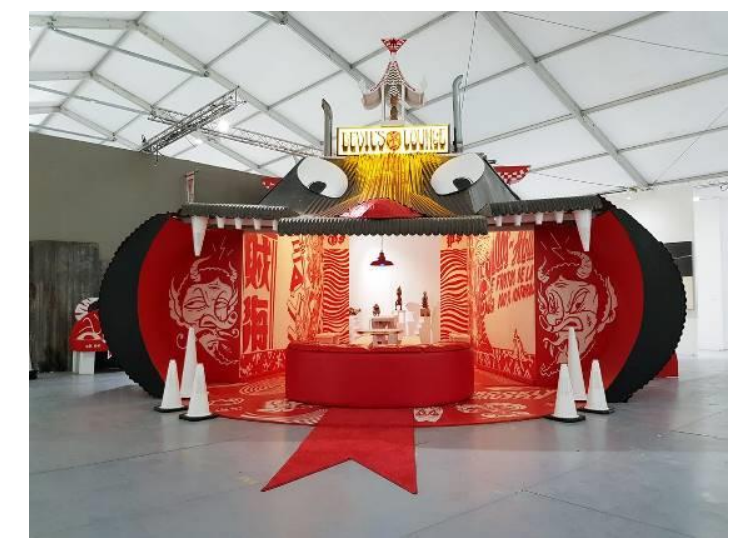

Gambar 1. Instalasi The Devil's Lounge.

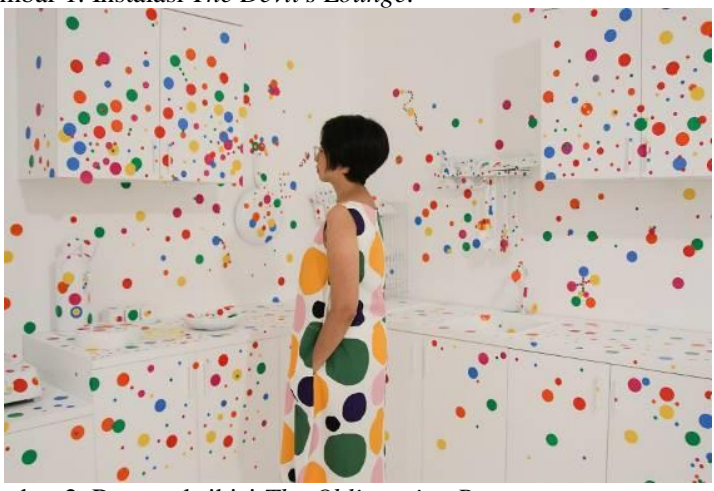

Gambar 2. Ruang eksibisi The Obliteration Room.

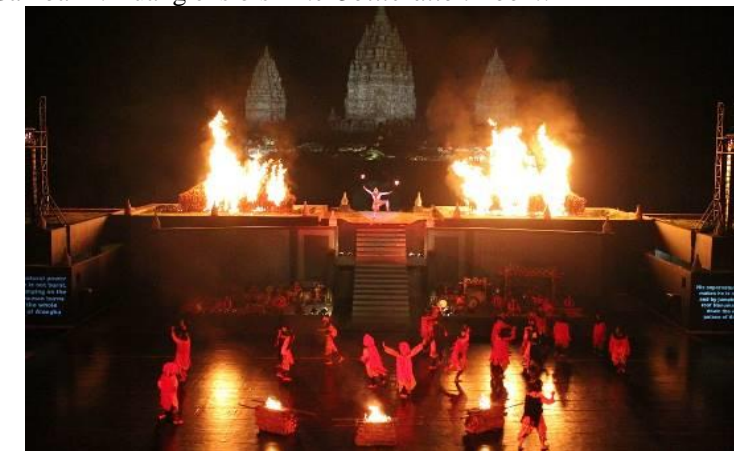

Gambar 3. Adegan Hanoman Obong di pementasan Sendratari Ramayana.

Perancangpun melakukan melakukan observasi mengenai replika relief epos Ramayana Candi Prambanan dan wawancara di Museum Sanggar Gubug Wayang, Mojokerto. Selain itu, dalang sekaligus guide di Museum Sanggar Gubug Wayang, Bayu Nagara mengatakan bahwa epos Ramayana memang banyak dipentaskan dengan berbagai jenis wayang, dan berbagai sudut pandang cerita. Berdasarkan kuesioner terhadap target audiens berumur 18 sampai 30 tahun, dapat diketahui bahwa dari festival tersebut pengunjung mencari pengetahuan $(85 \%)$, hiburan $(82 \%)$, pengalaman unik $(76 \%)$ 


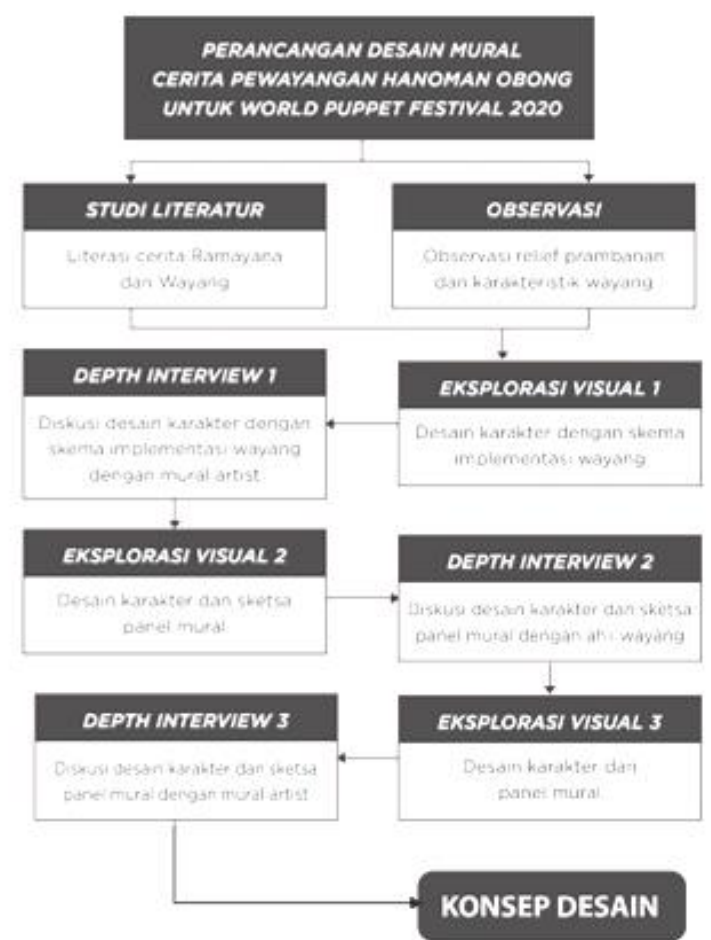

Gambar 4. Bagan alur perancangan.

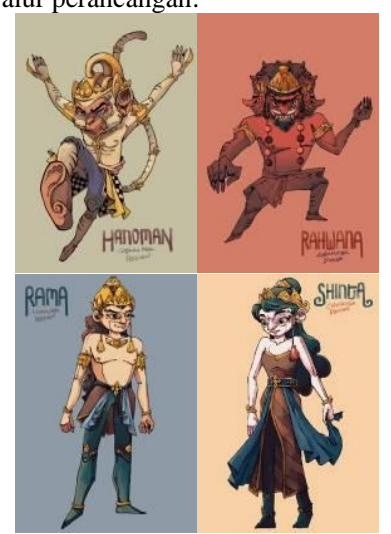

Gambar 5. Sketsa desain karakter Hanoman Obong.

dan kenangan (54\%). Media pilihan target audiens yang dapat memenuhi hal tersebut diantaranya pop-up exhibition (79\%), merchandise (77\%), dan mural installation (65\%).

Melalui riset media tersebut, perancang ingin mengenalkan keragaman tersebut sekaligus memeriahkan World Puppet Festival dengan media mural. Setelah melakukan wawancara dengan Presiden UNIMA, T. A. Samodra Sriwidjaja, penulis melihat potensi pop-up mural installation. Perpaduan pop-up exhibition dan mural installation yang menceritakan Hanoman obong dengan dua sudut pandang yang berbeda dengan interaksi berupa berbagai aktivitas yang dilakukan oleh pengunjung sehingga ada experience yang didapat. Selain itu, peneliti juga merancang merchandise elemen visual yang menjadi kebutuhan.

\section{A. Rumusan Masalah}

Permasalahan yang diangkat oleh perancang adalah: "Bagaimana merancang desain pop-up mural installation cerita pewayangan Hanoman Obong yang interaktif untuk World Puppet Festiva?".

\section{B. Batasan Masalah}

Berikut merupakan batasan masalah yang ditetapkan:

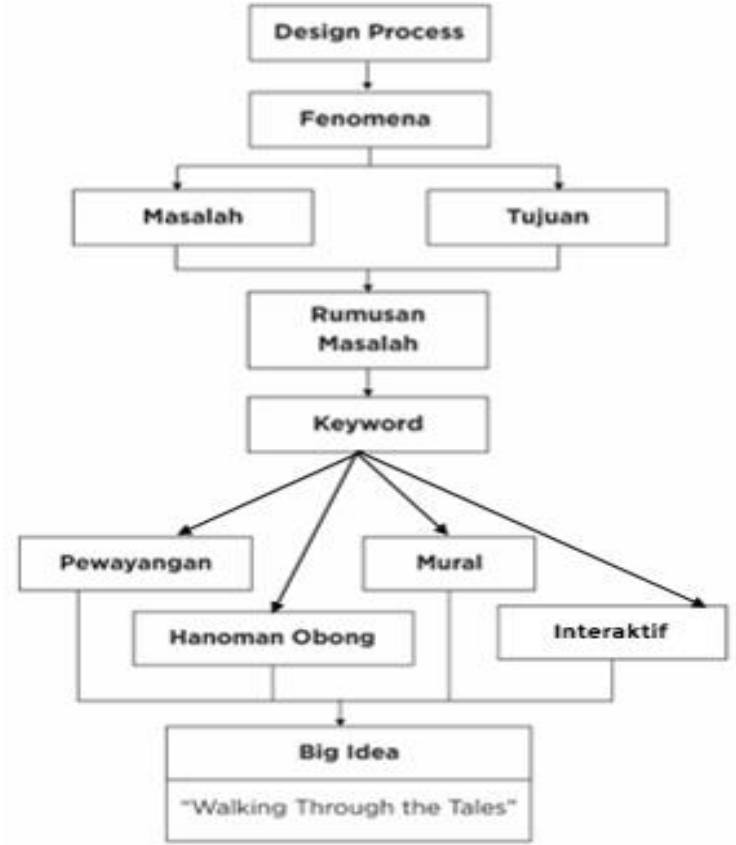

Gambar 6. Bagan Keyword Perancangan.
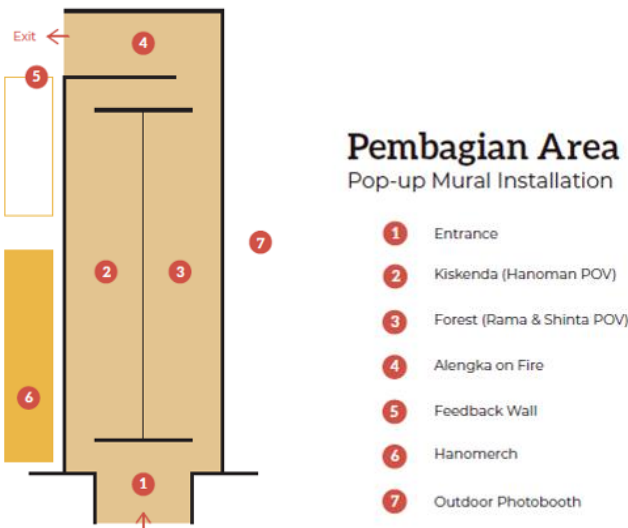

Gambar 7. Pembagian area
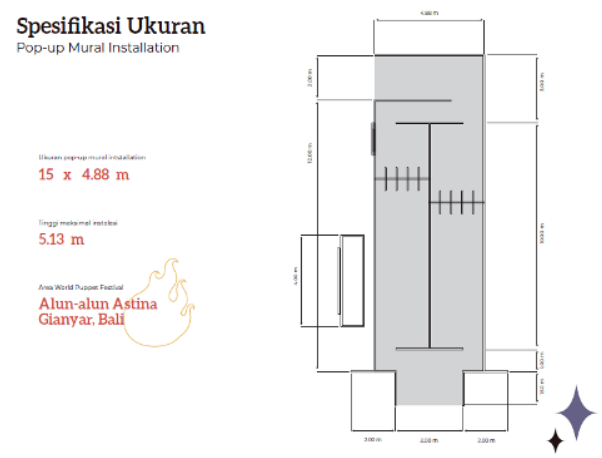

Gambar 8. Spesifikasi ukuran Pop-up Mural Installation.

1. Perancangan ini akan menyelesaikan permasalahan yang berkaitan dengan media pengenalan keragaman cerita pewayangan Indonesia untuk World Puppet Festival kepada pengunjung dengan usia 18-30 tahun.

2. Perancangan ini menggunakan multi-sensori yaitu tidak hanya menggunakan indra visual, tetapi juga perabaan dan juga gerak. Lingkungan interaktif mengharuskan pengunjung untuk memilih, dan mengeksplorasi penghayatan melalui aktivitas menempel sticker, menyetempel guide booklet, dan mengikuti alur yang dibuat.

3. Cerita yang akan diangkat dalam penelitian ini akan berfokus pada segmen cerita Hanoman Obong dari 


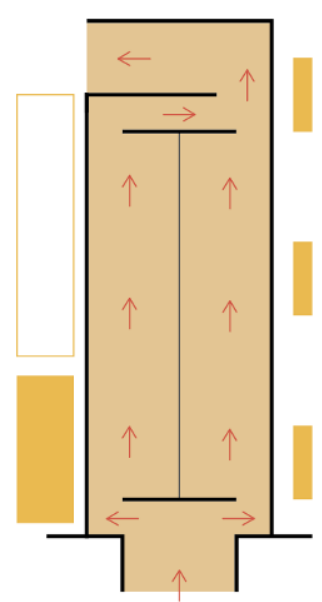

Gambar 9. Alur Sirkulasi Pengunjung.

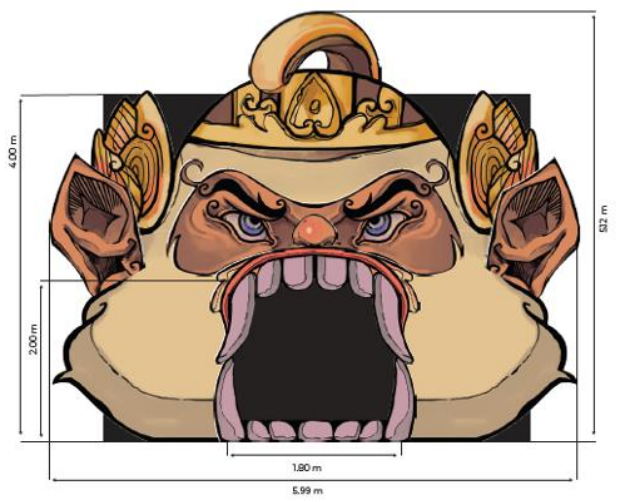

Gambar 10. Penjabaran Ukuran dan Layering pada Entrance Gate.

kisah Ramayana yang diceritakan melalui dua alur yang berbeda

4. Karakter Hanoman Obong yang digambarkan dalam perancangan ini meliputi empat karakter utama yaitu Hanoman, Rama, Shinta, dan Rahwana, dengan karakter figuran Subali, Sugriwa, Kalamarica dan Trijata.

5. Guide booklet dalam perancangan ini digunakan untuk mendukung interaksi pengunjung dengan instalasi maupun antar pengunjung.

6. Perancangan ini akan menghasilkan desain lingkungan pop-up mural installation, guide booklet, dan merchandise untuk World Puppet Festival 2020.

\section{TINJAUAN PUSTAKA}

\section{A. Teori Wayang}

Pertunjukkan wayang adalah bentuk teater yang berusia amat tua. Asal-muasal wayang berasal dari Jawa asli, bukannya meniru atau mencontoh dari Hindu, dengan argumen nama-nama peralatan wayang semua adalah kata asli Jawa; adanya wayang itu sudah semenjak sebelum bangsa Hindu datang ke Jawa; struktur lakon wayang digubah menurut model yang amat tua; cara bercerita ki dalang (tinggi rendah suaranya, bahasanya, dan ekspresi-ekspresinya) juga mengikuti tradisi yang amat tua; desain teknis, gaya susunan lakon-lakon ini juga bersifat khas Jawa. Menyaksikan pagelaran wayang sama artinya dengan bercermin. Masalahmasalah yang tersirat dalam lakon-lakon pewayangan memiliki makna sendiri-sendiri. Tak jarang cerminan lakonlakon pewayangan acap dijadikan suri teladan. Wayang mampu menyuguhkan pendidikan dan pengetahuan tanpa menggurui sekaligus menghibur[1]-[3].
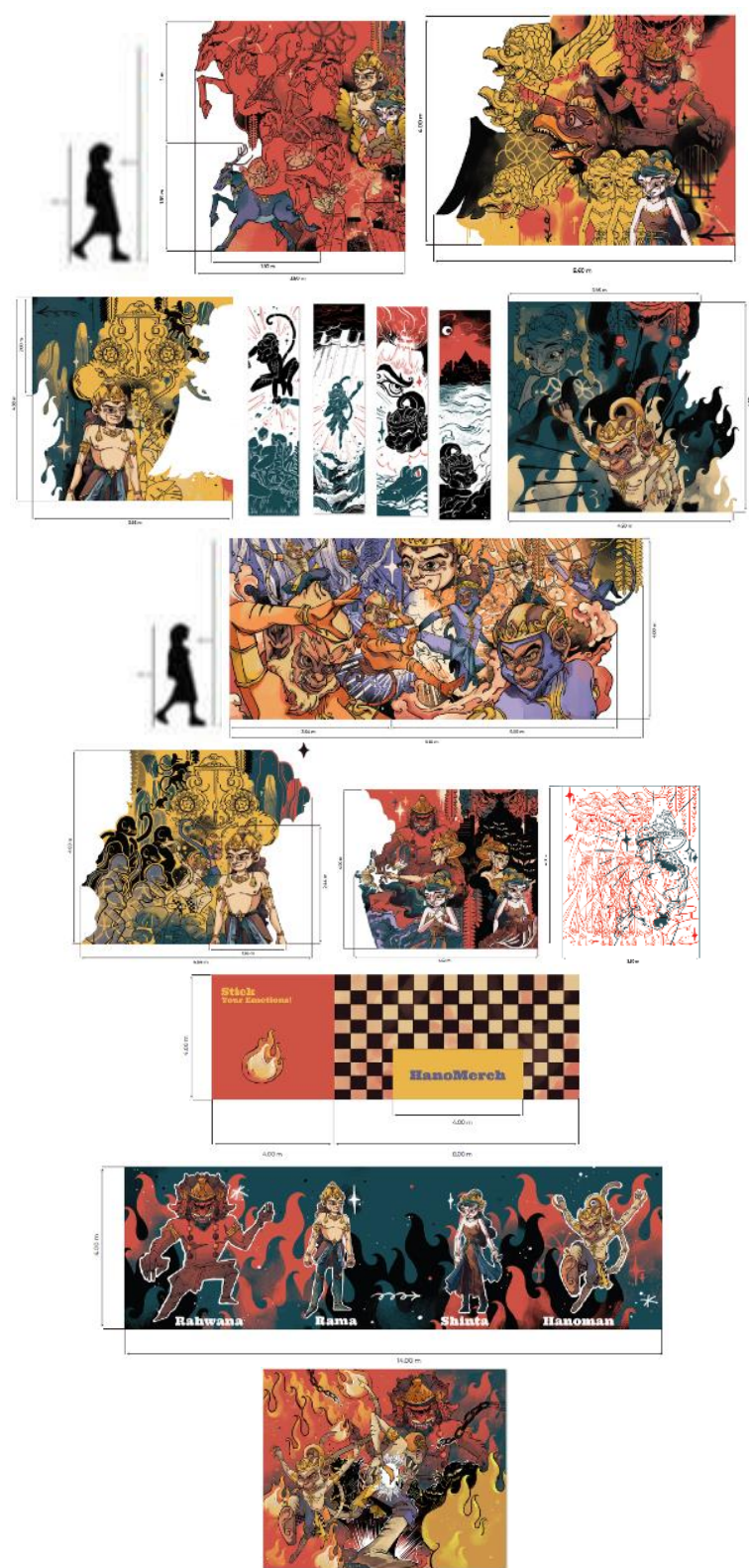

Gambar 11. Hasil Desain Mural.

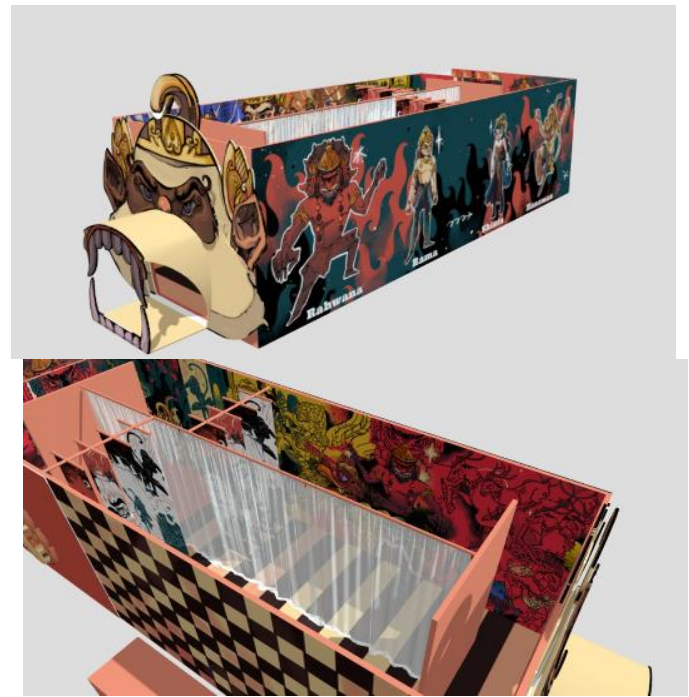

Gambar 12. Simulasi Penempatan Mural.

\section{B. Teori Bahasa Rupa}

Teori-teori yang digunakan dalam implementasi visual Wayang ke dalam perancangan, sesuai dengan buku Bahasa 
Rupa karya Prof. Dr. Primadi Tabrani. Di Indonesia sejak jaman kolonial, Naturalis-Perspektif-Momenopname (NPM) diajarkan di SD sampai saat ini, (gambar dua gunung dengan perspektip jalan, pohon kelapa, tiang listrik dan sebagainya) namun anak-anak tampak menggunakan sistem menggambar yang berbeda. Gambar anak dan gambar tradisional dapat dibaca dengan bahasa rupa, suatu ilmu yang mempelajari Ruang-Waktu-Datar (RWD). RWD belum ada dalam literatur barat. Selain itu perancang juga menggunakan Framework implementasi visual wayang ke desain karakter oleh Toto Haryadi[4], [5].

\section{Teori Eksibisi Kontemporer}

Teori mengenai eksibisi kontemporer yang akan digunakan dalam perancangan pop-up mural installation ini. Pameran kontemporer adalah suatu media penyampaian gagasan kepada khalayak umum pada ruang pamer dengan konsep modern / mengikuti perkembangan zaman. Teori-teori tersebut mencakup prinsip ruang eksibisi, kebutuhan ruang eksibisi dan standar ruang eksibisi.

\section{Teori Interaktivitas}

Teori ini membahas mengenai interaksi dalam ruang eksibisi, yaitu ketika pengunjung aktif melakukan penafsiran dan refleksi karena mampu merelasikan dirinya dengan objek, pesan yang ingin disampaikan dan nilai lebih mudah diingat. Ketika pengunjung mampu merelasikan konteks pameran dengan konteks kekinian, atau ketika mendapat informasi yang bernilai secara natural ia akan menceritakan pengalaman tersebut kepada lingkungan sosialnya. Lingkungan interaktif mengharus-kan audiensnya untuk memilih, meng-ubah, dan mengeksplorasi penghayatan-nya melalui gambar, film, teks, dan lain-lain. Selain itu, media interaktif memiliki beberapa kekuatan, dalam perancangan ini kekuatan yang digunakan mencakup integrity, interactivity, narrativity, dan immersion[6], [7].

\section{E. Studi Eksisting}

Studi eksisting digunakan untuk mengkaji dan mengadaptasi beberapa komparator yang dapat menjadi referensi yang baik untuk perancangan ini. Adapun eksisting yang ditinjau adalah The Devil's Lounge karya YOK and SHERYO, pop-up mural oleh Muklay dan mural Sandiwara oleh Nalta097 untuk instalasi mural, The Obliteration Room oleh Yayoi Kusama untuk interactive exhibition, Sendratari Ramayana di pelataran Candi Prambanan untuk cerita pewayangan seperti pada Gambar 1.

Perancangan ini menjadikan The Devil's Lounge sebagai acuan dalam adaptasi karakter Devil membuat gate instalasi, dan implementasi mural pada interior instalasi seperti pada Gambar 2.

Sementara itu, The Obliteration Room digunakan sebagai acuan dalam lingkungan interaktif. Hal yang ditinjau adalah interaksi pengunjung terhadap ruang eksibisi menggunakan sticker yang dapat ditempel dapat dilihat pada Gambar 3.

Sendratari Ramayana digunakan sebagai acuan dalam menceritakan epos Ramayana. Hal yang ditinjau adalah pembagian epos Ramayana dalam segmen-segmen sehingga penonton mudah mengikuti alur; inovasi dalam mengolah visual wayang ke dalam properti dan kostum pementasan; dan adanya alternatif narasi multibahasa untuk turis mancanegara.

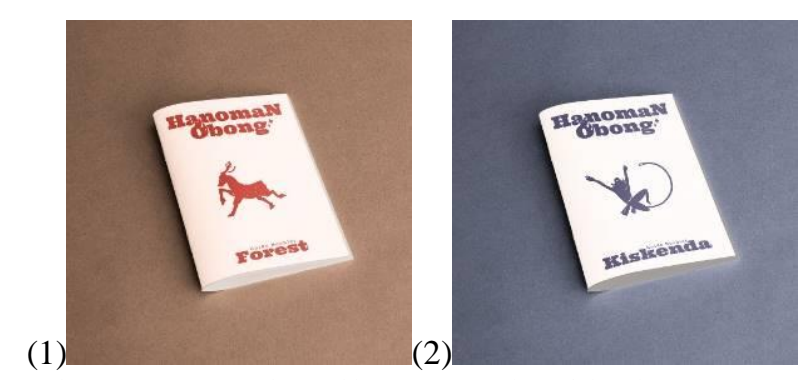

Gambar 13. Cover Guide Booklet Forest (1) dan Kiskenda (2).
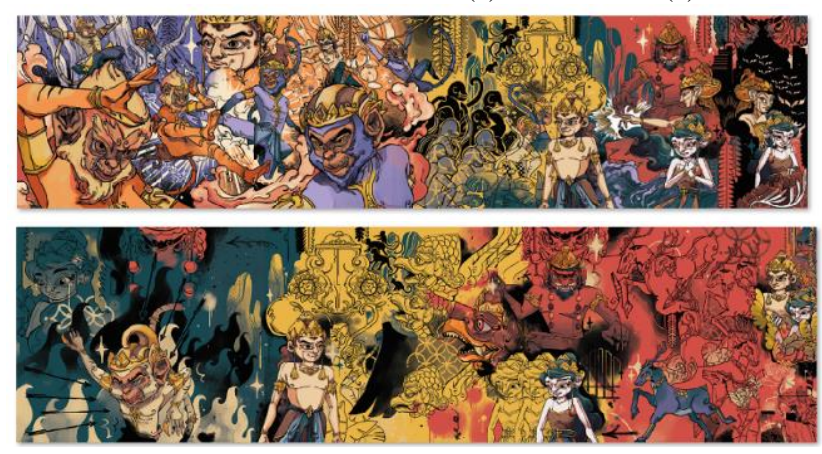

Gambar 14. Ilustrasi pada Area Kiskenda (atas) dan Forest (bawah)

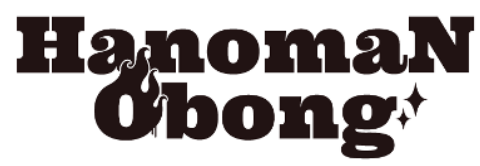

Gambar 15. Modifkasi font Ultra untuk logotype.

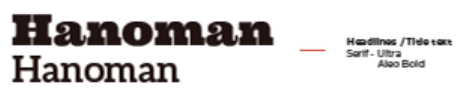

Hanoman

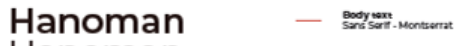

Hanoman

Gambar 16. Jenis Font yang Digunakan.
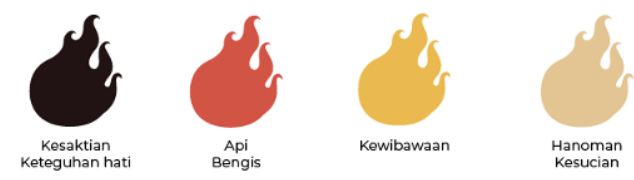

Gambar 17. Warna Primer Perancangan.

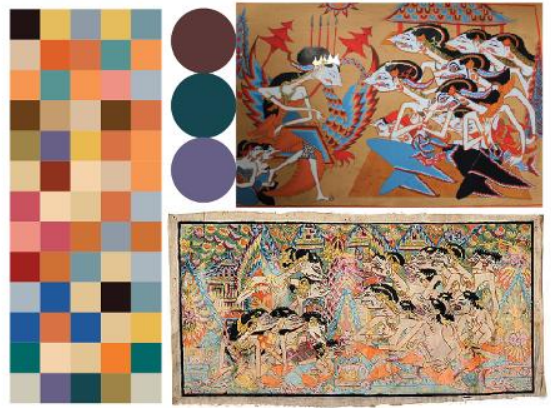

Gambar 18. Warna Sekunder dan Color Palette

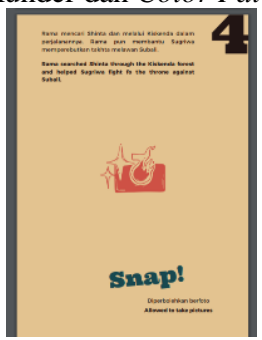

Gambar 19. Contoh Halaman Guide Booklet Forest. 


\section{METODOLOGI PENELITIAN}

Terdapat beberapa lagkah riset sebelum nantinya pop-up mural installation akan dibuat. Keempat riset tersebut adalah studi literatur, kuisioner, wawancara, dan observasi dapat dilihat pada Gambar 4.

Berikut merupakan metode yang digunakan beserta hasil yang diharapkan:

- Studi Literatur (landasan teori); studi literatur digunakan untuk panduan dalam perancangan ini. Teori yang digunakan adalah teori wayang, bahasa rupa, eksibisi kontemporer, dan interaktivitas.

- Studi Literatur (studi eksisting); studi eksisting digunakan untuk mengkaji dan mengdaptasi beberapa eksisting terdahulu dalam mural, instalasi, dan konten cerita.

- Kuesioner: kuesioner dilakukan terhadap 100 responden sesuai dengan target audiens. Kuesioner menanyakan pemahaman mengenai tema wayang, pengetahuan seputar World Puppet Festival, serta preferensi media dari audiens.

- Wawancara stakeholder; wawancara dengan Presiden UNIMA (Union Internationale de la Marionette) Indonesia untuk konfirmasi dan validasi draft naskah narasi, ilustrasi dan desain pop-up mural installation Hanoman Obong.

- Wawancara mural artist; wawancara dengan mural artist yaitu Dai Kurniawan (Nalta097) untuk konsultasi teknik mural dan diskusi draft desain karakter Hanoman Obong.

- Wawancara ahli wayang; wawancara dengan ahli wayang yaitu Bayu Nagara untuk konsultasi storyline dan draft desain pop-up mural installation Hanoman Obong.

- Observasi (Museum Sanggar Gubug Wayang Mojokerto): observasi dilakukan di Museum Sanggar Gubug Wayang Mojokerto untuk mengambil data berupa foto-foto replika relief Ramayana Candi Prambanan sebagai acuan dan dipelajari dalam perancangan.

Hasil dan analisis seluruh metode yang telah dipaparkan tersebut akan digunakan untuk menemukan konsep pop-up mural installation yang akan dirancang pada perancangan ini.

\section{ANALISIS DAN PENELITIAN}

\section{A. Analisis Cerita}

Cerita yang akan digunakan pada output merupakan kisah Hanoman Obong dari epos Ramayana. Cerita pewayangan sendiri umumnya memiliki banyak sudut pandang dan alur yang berbeda. Cerita pewayangan juga memiliki nilai-nilai yang dapat diterapkan dalam kehidupan. Penulis mengambil kisah Hanoman Obong karena pada World Puppet Festival, delegasi Indonesia menampilkan keberagaman pewayangan Indonesia. Salah satunya lakon Gugurnya Dasamuka, salah satu bagian epos Ramayana yang dipentaskan dengan Wayang Golek. Maka perancang ingin mengenalkan sudut pandang lain dari epos Ramayana melalui Hanoman Obong.

Dari hasil interview dengan Bayu Nagara, perancang mendapatkan storyline alternatif Hanoman Obong selain melalui kisah cinta Rama dan Shinta. Perancang mendapatkan storyline melalui kisah Hanoman dari Kiskenda yang membantu Sugriwa dalam berebut Dewi Tara dan takhta Kiskenda. Bumbu cerita dapat ditambahkan untuk membuat narasi menjadi lebih menarik.

\section{B. Analisis Karakter}

Karakter-karakter yang diimplementasikan oleh perancang dari wayang ke desain karakter merupakan empat karakter utama dari kisah Hanoman Obong yang diangkat. Setiap karakter memiliki karakteristik dan watak yang berbeda. Penggambaran mengadaptasi dari wayang kulit dan wayang golek. Dalam proses penggambaran karakter, perancang membreakdown ciri-ciri khusus pada wayang dan diimplementasikan dengan gaya gambar NPM menggunakan framework implementasi yang dibuat oleh Toto Haryadi dapat dilihat pada Gambar 5.

\section{Analisis Desain}

Perancangan mengadaptasi beberapa prinsip Bahasa Rupa sesuai gambar tradisi di Indonesia. Perancang menutuskan untuk menggunakan pewarnaan dengan teknik yang cukup kompleks dengan elemen-elemen visual khas street art menggunakan cat semprot dan cat tembok. Keputusan ini diambil berdasarkan tren street art performance dan exhibition dalam festival-festival skala nasional dan internasional. Untuk warna, perancang menutuskan untuk dominan menggunakan warna primer dan sekunder dengan paduan color palette yang mengadaptasi warna pada Wayang Beber.

Untuk memfokuskan alur cerita, adegan penting digambar dengan detil dan full rendered sedangkan background menggunakan outline atau siluet. Hal ini juga dapat memberikan efek kedalaman pada mural.

\section{Analisis Pop-up Mural Installation}

Untuk analisis pop-up mural installation, menurut hasil wawancara dengan stakeholder dapat dibangun di area alunalun Astina, Gianyar. Mural dibangun di alun-alun sebagai pusat opening festival. Kekurangan area ini adalah mural hanya berukuran akan berada di area yang sama dengan rangkaian acara lainnya, seperti opening ceremony, pementasan berbagai wayang, dan pementasan puppetry dari delegasi negara lain.

Material yang dipakai untuk konstruksi adalah plywood dan rangka aluminium. Untuk mural dikerjakan di atas plywood sesuai dengan desain yang sudah dibuat, untuk layering pada mural menggunakan plywood yang sudah dicutting laser. Sedangkan material tambahan lainnya adalah kain transparan untuk tirai di dalam instalasi.

\section{IMPLEMENTASI DESAIN}

Implementasi Design pada penilitian ini dapat dilihat pada Gambar 6.

\section{A. Konsep Desain}

Kesimpulan dari fenomena dan permasalaan perancangan ini adalah World Puppet Festival 2020 memerlukan media kontemporer untuk memeriahkan sekaligus memperkenalkan keragaman pewayangan Indonesia. Media kontemporer yang digunakan yaitu pop-up mural installation. Selain pop-up mural installation, juga dirancang media pendamping. Dengan demikian, pada perancangan ini ada pop-up mural installation sebagai media penyampaian cerita Hanoman Obong yang efektif dan guide booklet sebagai panduan dalam 
melakukan interaksi. Mural dirasa dapat menyampaikan cerita Hanoman Obong melalui lingkungan interaktif sehingga diharapkan dapat memberikan experience kepada pengunjung festival.

\section{1) What to Say}

Yang ingin disampaikan melalui perancangan ini adalah epos Ramayan pada segmen Hanoman Obong dikisahkan kepada pengunjung World Puppet Festival melalui dua alur yang berbeda dengan konsep "Walking Through the Tales". Konsep pesan yang ingin disampaikan melalui big idea tersebut adalah ingin mengajak pengunjung event World Puppet Festival untuk masuk ke dalam kisah dan mengenal serta mengetahui kisah Hanoman Obong dengan memberikan kenangan unik melalui interaksi dengan harapan audiens dapat memahami nilai-nilai dalam Hanoman Obong di era modern ini.

\section{2) How to Say}

Penyampaian kisah Hanoman Obong menggunakan cara yang menyenangkan melalui interaksi multi-sensori yaitu tidak hanya menggunakan indra visual, tetapi juga perabaan dan juga gerak. Pengunjung diajak untuk melakukan aktivitas menempel sticker, menyetempel guide booklet, dan mengikuti alur yang dibuat. Aktivitas dibuat sederhana agar pengunjung tidak kelelahan dan tetap bisa menikmati mural.

Untuk narasi kisah Hanoman Obong disampaikan melalui guide booklet menggunakan gaya bahasa bilingual yang sederhana dan menyenangkan dengan cara menyelipkan beberapa slang words dalam petunjuk melakukan interaksi pada tiap narasi. Font yang digunakan merupakan font serif dan sans-serif dengan tingkat readability yang tinggi. Selain readability yang tinggi, font pada title text dan body text tidak terlalu dekoratif karena menyeimbangkan ilustrasi pada mural yang sudah detil.

Hanoman Obong divisualisasikan dengan menggunakan gaya gambar yang mengadaptasi beberapa prinsip bahasa rupa dan dipadukan dengan gaya post-modern pada street art. Warna yang digukan mengadaptasi dari warna yang sering ditemui pada Wayang Golek, Wayang Kulit, dan Wayang Beber.

Sementara itu guide booklet akan dipilih oleh pengunjung di entrance gate. Dalam guide booklet juga terdapat kisscut stickers untuk melakukan interaksi dan memberikan feedback di exit gate. Terdapat halaman untuk menuliskan kesan terhadap pop-up mural installation, dan juga tempat menyelipkan foto. Guide booklet ini dapat dibawa pulang sebagai kenang-kenangan dan diharapkan dapat memberikan experience yang unik sehingga pengunjung dapat memahami kisah Hanoman Obong lalu menceritakan kembali kepada orang-orang terdekatnya.

\section{B. Kriteria Desain}

Dengan adanya output yang berasal dari konsep dasar kemudian dibuatlah kriteria desain yang menyesuaikan ruang lingkup. Kriteria desain merupakan suatu kriteria yang dipakai perancang sebagai pedoman untuk merancang. Berikut ini merupakan kriteria desain yang dibuat :

- Pop-up mural installation membentuk suasana yang mencerminkan nilai-nilai kesetiaan dan heroisme dalam Hanoman Obong.
- Perancangan dapat mengenalkan keberagaman pewayangan Indonesia melalui pop-up mural installation dalam festival.

- Pembentukan environmental design berupa eksibisi kontemporer yang berkonsep "Walking Through the Tales".

- Penyampaian kisah Hanoman Obong dalam desain melalui dua alur yang berbeda sampai berakhir saat Hanoman membakar Alengka, dikemas dengan gaya kontemporer.

- Pemberian experience melalui interaktivitas pada narasi yang dilalui pengunjung.

\section{Konsep Konstruksi}

Pembagian area pop-up mural installation berdasarkan dua alur Hanoman Obong yang berbeda dapat dilihat pada Gambar 7. Yaitu melalui sudut pandang Hanoman melalui area Kiskenda, dan sudut pandang kisah cinta Rama \& Shinta melalui area Forest. Kedua area ini nantinya akan bertemu di area Alengka on Fire sebagai puncak kisah Hanoman Obong. Pada bagian luar instalasi terdapat outdoor photobooth, dinding untuk menempel feedback sticker, dan merchandise booth.

Karena pada lokasi World Puppet Festival tidak terdapat dinding yang dapat dijadikan alas mural, maka perlu dibangun konstruksi dinding yang terdiri dari rangka besi dan dinding mural. Rangka besi yang digunakan memiliki kelebihan yaitu tahan panas, tidak mudah lapuk, dan tahan lama. Sedangkan untuk material dinding mural menggunakan plywood atau multiplek yang disusun, dan dalam beberapa bagian dicutting laser untuk layering pada instalasi. Di bawah ini merupakan spesifikasi ukuran keseluruhan pada pop-up mural installation dapat dilihat pada Gambar 8.

\section{Konsep Kegiatan}

Pop-up mural installation yang ada pada World Puppet Festival 2020 yang diadakan di Alun-alun Astina, Gianyar, Bali. Instalasi dapat diakses pengunjung sesuai dengan pelaksanaan opening festival. Adapun ketentuan memasuki pop-up mural installation adlah sebagai berikut:

- Free entry untuk pengunjung festival

- Setiap pengujung yang masuk memilih area Forest atau Kiskenda dan mengambil guide booklet.

- Mengikuti petunjuk yang ada pada guide booklet

- 1 Kloter terdiri dari 7 hingga 15 orang

- Batasan waktu setiap kloter adalah 20 menit, namun pengujung dapat masuk kembali tetapi tidak mengambil booklet berikutnya.

- Di pintu keluar booklet akan dicek, apabila tidak ada sticker yang digunakan maka booklet akan diambil kembali, namun jika pengujung menggunakan sticker untuk berinteraksi di dalam maka guide booklet boleh dibawa pulang.

- Foto yang diambil oleh staff dapat diambil di Hanomerch. Sementara itu, untuk alur memasuki pop-up mural installation dimulai dari memasuki entrance gate dan memilih booklet Kiskenda atau Forest. Lalu pengujung mengikuti arahan dari booklet dan mengikuti interaksi dan aktivitas yanga ada, selanjuutnya kedua jalur tersebut akan bertemu di area Alengka on Fire sebelum pintu keluar dapat dilihat pada Gambar 9. 


\section{E. Implementasi Desain}

1) Layout Mural

Pembagian area berdasarkan dua storyline yang berbeda. Area Forest berangkat dari penculikan Shinta yang terjadi saat Rama, Shinta, dan Laksmana berburu ke hutan. Sedangkan Area Kiskenda berangkat dari perebutan takhta Kiskenda oleh Subali dan Sugriwa, kemudian Rama yang dalam perjalanan mencari Shinta ikut menolong, dan Hanoman membantu Rama mencari Shinta. Kedua area ini bertemu di area Alengka sebelum pintu keluar. Secara garis besar kisah ini berangkat dari penculikan Shinta oleh Rahwana dengan klimaks pembakaran kerjaan Alengka saat Haloman melarikan diri. Pop-up mural installation ini terdapat di area outdoor dan memiliki ukuran 15 meter x 4,88 meter dengan tinggi maksimal 5,1 meter dapat dilihat pada Gambar 10 - 12 .

\section{2) Guide Booklet}

Pembagian konten setiap area ini dibagi menjadi tiga yaitu story merupakan kisah yang disampaikan melalui mural; activity merupakan aktivitas yang dilakukan pengunjung, baik itu interaksi dengan instalasi maupun dengan pengunjung lainnya; sedangkan installation merupakan apa saja yang ada pada pop-up mural installation.

Guide booklet yang diambil oleh pengunjung di pintu masuk berisi tentang petunjuk dan aktivitas apa saja yang dilakukan oleh pengunjung. Di dalam booklet terdapat kisscut stickers yang dapat ditempel sesuai petunjuk dan menjadi feedback dari pengunjung dapat dilihat pada Gambar 13.

\section{3) Ilustrasi}

Dalam perancangan ini ilustrasi memenuhi dinding pop-up mural installation, dan media pendukung lainnya. Ilustrasi menggabungkan konsep NPM dan RWD, yaitu menggambar dengan cara modern dan bahasa rupa. Dengan mengadaptasi beberapa prinsip bahasa rupa. Ilustrasi menceritakan kisah Hanoman Obong sesuai dengan alur dari Kiskenda dan Forest lalu berkahir di Alengka. Selain itu, ilustrasi juga terdapat di kisscut sticker sheet untuk guide booklet.

- Tipografi

Tipografi yang digunakan menggunakan font serif dengan mode bold untuk logotype, dan sans-serif untuk body text. Namun pilihan font tetap bertipe simpel supaya memiliki tingkat readibility yang tinggi serta menyeimbangkan desain mural yang penuh dengan detil seperti pada Gambar 15 - 16 .

\section{- Warna}

Warna primer yang digunakan dalam perancangan ini menggunakan warna-warna yang sering dijumpai di wayang Bali, wayang Kulit, hingga wayang Golek dapat dilihat pada Gambar 17.

Warna sekunder dan palet warna yang digunakan dalam perancangan ini menggunakan adaptasi warna yang ada di wayang Beber, wayang tertua di Indonesia yang dibuat di atas kertas kekuningan bernama dlancang gedhog dapat dilihat pada Gambar 18.

\section{- Gaya Bahasa}

Gaya bahasa yang digunakan pada mural dan guide booklet ini menggunakan bahasa yang sederhana, tidak bertele-tele, dan menggunakan beberapa kata tidak baku. Perancang menggunakan dua bahasa yaitu bahasa Indonesia dan bahasa Inggris. Kata-kata tidak baku atau slang digunakan dalam booklet. Seperti "snap" Yang berarti "cekrek" dalam pelafalan bahasa Indonesia seperti pada Gambar 19.

\section{F. Kesimpulan}

Kesimpulan yang didapat pada perancangan ini dilihat dari beberapa variabel, yaitu:

1) Media

Perancang menyelesaikan permasalahan yang dirumuskan menggunakan desain pop-up mural installation Hanoman Obong yang interaktif dan berpotensi untuk mengenalkan keragaman pewayangan Indonesia di World Puppet Festival. Instalasi dibangun di lokasi opening festival.

\section{2) Target}

Pop-up mural installation Hanoman Obong ini dapat dikunjungi oleh pengunjung World Puppet Festival serta delegasi negara anggota UNIMA dengan target utama umur 18-30 selama rangkaian 23rd UNIMA Congress World Puppet Festival berangsung. Pengunjung akan memilih jalur Forest atau Kiskenda di entrance gate kemudian mendapatkan guide booklet yang berisi narasi mural dan panduan interaksi melalui aktivitas yang akan dilakukan di dalam area.

3) Konten

Konten cerita yang diangkat dalam perancangan ini berfokus pada segmen cerita Hanoman Obong dari kisah Ramayana. Diceritakan melalui dua alur yang berbeda yaitu dari percintaan Rama dan Shinta, dan yang kedua melalui Hanoman dari Kiskenda. Kedua alur ini bertemu di area yang sama yaitu saat Hanoman membakar Alengka.

Interaksi yang dilakukan oleh pengunjung meliputi multisensori melalui aktivitas menempel sticker, menyetempel pilihan kalimat rumpang, serta berjalan mengikuti alur cerita bertujuan agar pengunjung dapat merasakan pengalaman yang unik dan lebih mudah memahami Hanoman Obong.

\section{4) Konstruksi}

Hasil akhir konsep berupa sebuah desain pop-up mural installation dengan ukuran 15 meter x 4,88 meter yang akan diletakkan di Alun-alun Astina, Gianyar, Bali, pada April 2020. Dibangun menggunakan material plywood untuk sekat dan rangka aluminium.

\section{5) Aspek Visual}

Elemen visual yang digunakan dalam perancangan ini diambil dari riset yang telah dilakukan oleh perancang. Warna primer yang digunakan mengadaptasi dari warnawarna yang sering ditemui di Wayang Golek, Wayang Kulit, sedangkan untuk warna sekunder dan palet warna yang digunakan mengadaptasi Wayang Beber. Ilustrasi yang digunakan adalah implementasi RWD ke gaya gambar diadaptasi perancang dari post-modern khususnya street art, yang meliputi mural, graffiti dan graffiti characters. Elemen visual yang digunakan juga mengadaptasi efek dan teknik pada street art.

Tipografi pada logo dan headlines/title text menggunakan Ultra Bold, dan untuk bodytext menggunakan font Aleo Bold dan family font Montserrat. Narasi yang digunakan merupakan bilingual yaitu bahasa Indonesia dan bahasa Inggris. Gaya bahasa yang digunakan menggunakan kalimat sederhana yang pada beberapa bagian menggunaan kata slang agar tidak kaku dan menyenangkan untuk pengunjung.

\section{DAFTAR PUSTAKA}

[1] S. Padmosoekotjo, Silsilah Wayang Purwa Mawa Carita, Jilid 2. Surabaya: CV 'Citra Jaya, 1981

[2] R. M. Sajid, Ringkasan sejarah wayang: kutipan dan terjemahan ke 
dalam bahasa Indonesia dari naskah bahasa Jawa, Bau warna sejarah wayang. Jakarta, Indonesia: Pradnya Paramita, 1981.

[3] M. Sucipta, Ensiklopedia tokoh-tokoh wayang dan silsilahnya. Yogyakarta, Indonesia: Narasi, 2010

[4] T. Haryadi and K. Khamadi, "Perancangan Model Wujud Visual Tokoh Pewayangan dalam Pembentukan Identitas dan Watak Tokoh Sebaga Acuan Desain Karakter dalam Karya DKV," J. DeKaVe, vol. 7, no. 2, 2014.
[5] P. Tabrani, Bahasa rupa. Bale Endah, Kabupaten Bandung, Jawa Barat: Kelir, 2012.

[6] T. Austin and R. Doust, New Media Design (in the Portfolio Series). London: Laurence King Publishing Ltd., 2007.

[7] A. S. Azarja, J. Hidayat, and Fatmahwaty, Struktur desain naratif dan strategi desain multi-sensori untuk menciptakan pengalaman naratif yang interaktif. Tangerang: Universitas Pelita Harapan, School of Design, 2014 